\section{Influence of different types of noise on sentence recognition in normally hearing adults}

\author{
Matheus Carvalho Ferreira1 \\ https://orcid.org/0000-0003-0620-5659 \\ Nelma Ellen Zamberlan Amorim² \\ https://orcid.org/0000-0002-7150-3807
}

Aline Epiphanio Wolf ${ }^{1}$ https://orcid.org/0000-0001-5006-8482

Ana Cláudia Mirândola Barbosa Reis ${ }^{1}$ https://orcid.org/0000-0002-5152-5881
Universidade de São Paulo, Faculdade de Medicina de Ribeirão Preto - FMRP-USP, Curso de Fonoaudiologia, Ribeirão Preto, São Paulo, Brasil.

2 Universidade de São Paulo, Faculdade de Medicina de Ribeirão Preto - FMRP-USP, Hospital das Clínicas de Ribeirão Preto, Ribeirão Preto, São Paulo, Brasil.

This study was carried out at the Specialized Center for Otorhinolaryngology and Speech-Language-Hearing Pathology at the Clinics Hospital of Ribeirão Preto.

Conflict of interests: Nonexistent

\section{(c) (i)}

Received on: March 17, 2021 Accepted on: August 5, 2021

Corresponding address:

Ana Claudia Mirândola Barbosa Reis Departamento Ciências da Saúde

Rua Miguel Covian, 120 - Campus da USP CEP. 14049-900 - Ribeirão Preto, São

Paulo, Brasil

E-mail: anaclaudia@fmrp.usp.br

\section{ABSTRACT}

Objective: to analyze speech perception in normally hearing adults when listening in silence and with different types of noise.

Methods: 40 individuals of both sexes, aged 18 to 45 years, participated in the study. Speech perception was assessed with the Lists of Sentences in Portuguese test, without a competing noise and with speech-spectrum, babble, and cocktail party noise. A mixed-effects linear regression model and the 95\% confidence interval were used.

Results: the subjects' performance was worse in the three types of noise than in silence. When comparing the types of noise, differences were found in all combinations (speech-spectrum X babble, speech-spectrum X cocktail party, and babble $X$ cocktail party), with a worse performance in babble, noise, followed by cocktail party. Conclusion: all noises negatively influenced speech perception, with a worse performance in babble, followed by cocktail party and speech-spectrum.

Keywords: Speech Perception; Speech Intelligibility; Hearing Tests; Noise; Signal-ToNoise Ratio; Hearing; Audiology 


\section{INTRODUCTION}

Speech perception is a complex process in which the person linguistically processes sound information', involving various skills, capacities, and knowledge at different levels. Individuals must first identify the sound, and then discriminate it, according to its spectrum, duration, sequence, rhythm, and temporal characteristics. Finally, they must recognize, memorize, and understand the speech units within a given linguistic system ${ }^{1-3}$.

Speech perception may be influenced by various factors ${ }^{46}$, including the environmental conditions in which it occurs. Listening in noisy environments is a complex task that requires attention, memory, linguistic knowledge, and precise auditory-neurophysiological sound processing in all age groups ${ }^{7}$. Environments with intense noise may compromise speech perception, as they require greater concentration on the part of the listener, who needs to focus their attention on the target information and ignore the noise or competing speech ${ }^{8}$.

Understanding a spoken message requires a combination of acoustic, linguistic, semantic, and circumstantial cues. In favorable environments, without a competing noise, cues are abundant, and some of them may even be unnecessary to understand the message. However, in unfavorable conditions, with low redundancy, the cues are few, requiring greater effort and concentration from the listener ${ }^{9,10}$.

In audiological assessment, pure-tone thresholds and speech audiometry are not enough to fully measure a person's communicative ability and how they understand speech in daily listening situations ${ }^{11,12}$. For this reason, use speech recognition tests with or without a competing noise ${ }^{1,10-12}$ are also used, especially to assess the performance of patients with sound amplification devices, cochlear implants, or other devices, and to monitor their rehabilitation process.

When applying these tests, different types of speech stimuli (such as monosyllabic words and sentences) and different types of noise (such as continuous and speech noise) ${ }^{10}$ can be used. The sentence recognition test with competing noise is considered the most effective tool to evaluate speech perception, because it assesses auditory skills in conditions close to everyday hearing experiences, portraying such skills more reliably ${ }^{11,13}$. The Lists of Sentences in Portuguese test (LSP), the first one developed in Brazilian Portuguese, contains lists with 10 sentences each to be used as speech stimuli, presented both in silence and competing noise $\mathrm{e}^{11,13,14}$
White noise is a continuous, broadband noise with a wide frequency range - from 125 to $8000 \mathrm{~Hz}$ - used to assess speech perception ${ }^{8,10-13,15-19}$. Some studies have developed other types of continuous noise to create a competing signal whose spectrum is similar to that of the speech material they either used or developed in their research ${ }^{11-13,17-19}$. For instance, Costa et al. ${ }^{20}$ developed in their study a continuous speech-spectrum noise to be used along with LSP. They recorded 12 people speaking some of the LSP sentences and then filtered the white noise according to their speech spectrum ${ }^{20,21}$.

Babble and cocktail party stand out among the speech noises. Unlike continuous noise, the speech noises are aperiodic, and their intensity and frequency vary over time ${ }^{8,10,16,20}$. Babble is a speech-spectrum noise with minimal amplitude modulation, in which a group of people is talking but whose messages are incomprehensible to the listener. The cocktail party noise, on the other hand, resembles a party and thus contains both speech and environmental sounds ${ }^{8,16}$. Some studies use other competing noises, such as coffee-shop and amplitude-modulated noise ${ }^{8,10,15}$.

Speech noises are more detrimental to speech perception than continuous noises since they generate false cues and require more attention and memory from the listener ${ }^{8,10}$. Mantelatto ${ }^{16}$ found a worse performance in cocktail party than white noise when assessing a group of normally hearing young people. Another study ${ }^{8}$ obtained similar results assessing speech perception in silence, white noise, and cocktail party noise in three groups - one made up of normally hearing adults, the second, of adults with a hearing loss, and the third, of older adults with a hearing loss. The authors observed that, in all groups, the subjects performed worse with the cocktail party noise - which made it the most effective one to show the effects of hearing loss and age on speech perception. Other scholars ${ }^{10}$, when investigating schoolchildren's speech perception in silence, white noise, and babble noise, found a worse performance when using the last one. In a national study ${ }^{22}$, the authors assessed the speech perception of normally hearing adults with and without tinnitus complaints, with both LSP noise ${ }^{20}$ and calibrated speech noise from the audiometer they used (speechnoise - SN). They observed that both groups (with and without tinnitus complaints) had worse performance in speech noise. Comparing their performance, they also found that, although those with tinnitus had worse 
results with both noises, the difference was significant only when using speech noise.

Hence, the literature reports greater interference of speech noises in auditory speech perception tests. However, continuous noises with a spectrum based on sentence lists are little used when investigating types of noise and their influence on speech perception. In these cases, spread-spectrum noise is the most used. Moreover, further studies are necessary to investigate speech noises and find the most sensitive one to assess speech recognition, as the literature does not provide enough evidence to come to such a conclusion with absolute certainty ${ }^{4,8,10,16}$.

Understanding the various types of noise and their influence on speech perception can contribute to clinical practice by establishing better assessment conditions, closer to everyday listening situations, with more reliable portrayals of people's auditory perception. Hence, this study aimed to analyze speech perception in normally hearing young adults, in silence, and in three different types of noise: continuous speech-spectrum, cocktail party, and babble noise.

\section{METHODS}

This study was conducted at the Specialized Center for Otorhinolaryngology and Speech-LanguageHearing Pathology at the Clinics Hospital of the Ribeirão Preto School of Medicine at the University of São Paulo, Brazil and approved by the Research Ethics Committee of the originating institution, process no. 4223/2018.

This is a prospective, cross-sectional, comparative study. All research participants signed the informed consent form.

The sample comprised 40 normally hearing ${ }^{20}$ subjects of both sexes, aged 18 to 45 years, with no diagnosed cognitive changes. They were selected by convenience, and the sample size was established based on literature data.

The procedures were divided into four stages. The first was an interview to know the patient's health history and check whether they met the inclusion criteria. Next, their air-conduction hearing thresholds from 250 to $8000 \mathrm{~Hz}$ were studied. Lastly, speech perception tests with and without a competing noise, using supraaural earphones (TDH-39) in an acoustically controlled environment were conducted.

The hearing thresholds at 500, 1000, 2000, and $4000 \mathrm{~Hz}$ were averaged to obtain their degree of hearing loss. The hearing was considered normal when the mean threshold was up to $25 \mathrm{dBHL}^{20}$.

The LSP ${ }^{21}$ to assess speech perception was used. This test contains a list with 25 sentences (list $1 A)^{23}$, seven lists with 10 sentences each (lists 1B to 7B) ${ }^{24}$, and a continuous speech-spectrum noise ${ }^{17}$. They are recorded on a $C D$ and have been made available by the author.

For this research, lists $1 \mathrm{~A}, 1 \mathrm{~B}, 2 \mathrm{~B}, 4 \mathrm{~B}, 5 \mathrm{~B}$, and the continuous speech-spectrum noise from the $C D^{20}$ were used. List $1 \mathrm{~A}$ was used only for training. Lists $1 \mathrm{~B}$ (no noise) and 2B (with noise) were applied as originally recorded. Lists $4 B$ and $5 B$ were taken from the noiseless LSP material and recorded in the studio, respectively with babble and cocktail party noise.

After the recordings, a specialized professional analyzed the four lists (1B, 2B, 4B, and $5 \mathrm{~B}$ ) saved in .wav format with PRAAT acoustic spectral analysis program to ensure the quality of the presentation of the studio-recorded noises. The mean, maximum and minimum frequency and intensity values were extracted from the files.

No significant differences were observed between the lists after recording, as shown in Table 1.

Table 1. Mean frequencies and intensities of the 10 sentences used in the recording of the four tracks (1B, 2B, 4B, and 5B)

\begin{tabular}{ccccccc}
\hline Ranges & $\begin{array}{c}\text { Mean } \\
\text { Frequencies (Hz) }\end{array}$ & $\begin{array}{c}\text { Minimum } \\
\text { Frequency (Hz) }\end{array}$ & $\begin{array}{c}\text { Maximum } \\
\text { Frequency (Hz) }\end{array}$ & $\begin{array}{c}\text { Mean Intensity } \\
(\mathbf{d B})\end{array}$ & $\begin{array}{c}\text { Minimum } \\
\text { Intensity (dB) }\end{array}$ & $\begin{array}{c}\text { Maximum } \\
\text { Intensity (dB) }\end{array}$ \\
\hline 1B - NN & 101.99 & 74.31 & 188.81 & 71.48 & 44.28 & 78.74 \\
2B - WN & 100.81 & 90.61 & 110.37 & 71.55 & 68.46 & 75.81 \\
$\begin{array}{c}\text { CS } \\
\text { 4B - WN }\end{array}$ & 161.91 & 88.51 & 351.30 & 72.43 & 62.27 & 77.71 \\
$\begin{array}{c}\text { Babble } \\
\text { 5B - WN }\end{array}$ & 163.65 & 95.02 & 312.67 & 70.85 & 62.19 & 76.71 \\
Cocktail party & & & & & & \\
\hline
\end{tabular}

Captions: $\mathrm{Hz}=\mathrm{Hertz} ; \mathrm{dB}=$ decibel; $\mathrm{NN}=$ no noise; $\mathrm{WN}=$ with noise; $\mathrm{CS}=$ continuous speech-spectrum noise 
The test was performed first without noise and then with three different types of noise (continuous speechspectrum, babble, and cocktail party), at a $0 \mathrm{~dB}$ signalto-noise ratio. The first list was performed without noise, and the following three, with continuous speechspectrum, cocktail party, and babble noises.

To avoid presentation order as a variable, the sentence lists with the different noises were presented randomly to the participants.

After obtaining the data, a statistical analysis was made, and mixed-effects linear regression models were used, with $95 \%$ confidence intervals.

\section{RESULTS}

All three noises negatively influenced speech perception when compared to listening in silence. There was a difference in all possible comparisons for both ears: no noise $X$ continuous speech-spectrum noise $(p=0.0001$ for the right ear and $p=0.0003$ for the left ear), no noise $X$ babble noise $(p=0.0001$ for both ears), and no noise $X$ cocktail party noise ( $p=$ 0.0001 for both ears).

There were also differences between the tests with noise in all the possible comparisons for both right and left ears (Table 2).

Table 2. Comparison of speech perception in the different types of noise in the right and left ears

\begin{tabular}{ccccccc}
\hline \multirow{2}{*}{ Ear } & \multirow{2}{*}{ Noise } & Noise & $\begin{array}{c}\text { Estimated } \\
\text { Difference }\end{array}$ & p-value & \multicolumn{2}{c}{ 95\% Confidence Interval } \\
\cline { 6 - 7 } & & $\mathrm{B}$ & 7.73 & $0.0001^{*}$ & 4.93 & Upper Limit \\
\hline $\mathrm{RE}$ & $\mathrm{CS}$ & $\mathrm{CP}$ & 3.20 & $0.0253^{*}$ & 0.40 & 6.53 \\
$\mathrm{RE}$ & $\mathrm{CS}$ & $\mathrm{CP}$ & -4.53 & $0.0016^{*}$ & -7.33 & -1.73 \\
$\mathrm{RE}$ & $\mathrm{B}$ & $\mathrm{CS}$ & 7.01 & $0.0001^{*}$ & 4.21 & 9.81 \\
LE & $\mathrm{CS}$ & $\mathrm{B}$ & 3.37 & $0.0183^{*}$ & 0.57 & 6.17 \\
LE & $\mathrm{CS}$ & $\mathrm{CP}$ & -3.64 & $0.0110^{*}$ & -6.44 & -0.84 \\
LE & $\mathrm{B}$ & $\mathrm{CP}$ & &
\end{tabular}

*Statistically significant values $(p \leq 0.05)$ - mixed-effects linear regression model

Captions: $\mathrm{RE}=$ right ear; $\mathrm{LE}=$ left ear; $\mathrm{CS}=$ continuous speech-spectrum noise; $\mathrm{B}=$ babble; $\mathrm{CP}=$ cocktail party

However, there was no difference between the responses of the right and left ears in any of the listening situations (Table 3 ).
Moreover, no difference was found with respect to age in any of the four listening situations - i.e., no noise and continuous speech-spectrum, babble, and cocktail party noise (Table 4).

Table 3. Comparison between the responses of the right and left ears in the speech perception test without noise and with continuous speech-spectrum, babble, and cocktail party noise

\begin{tabular}{|c|c|c|c|c|c|c|}
\hline \multirow{2}{*}{ Noise } & \multirow{2}{*}{ Ear } & \multirow{2}{*}{ Ear } & \multirow{2}{*}{$\begin{array}{l}\text { Estimated } \\
\text { Difference }\end{array}$} & \multirow{2}{*}{$\mathrm{p}$-value } & \multicolumn{2}{|c|}{ 95\% Confidence Interval } \\
\hline & & & & & Lower Limit & Upper Limit \\
\hline NN & $\mathrm{RE}$ & $\mathrm{LE}$ & 0.17 & 0.9069 & -2.63 & 2.97 \\
\hline CS & $\mathrm{RE}$ & LE & -0.63 & 0.6561 & -3.43 & 2.17 \\
\hline B & $\mathrm{RE}$ & LE & -1.35 & 0.3432 & -4.15 & 1.45 \\
\hline $\mathrm{CP}$ & $\mathrm{RE}$ & LE & -0.46 & 0.7476 & -3.26 & 2.34 \\
\hline
\end{tabular}

Statistically significant values $(p \leq 0.05)$ - mixed-effects linear regression model

Captions: $\mathrm{RE}=$ right ear; $\mathrm{LE}=$ left ear; $\mathrm{NN}=$ no noise; $\mathrm{CS}=$ continuous speech-spectrum noise; $\mathrm{B}=$ babble; $\mathrm{CP}=$ cocktail party 
Table 4. Influence of age on the results of the speech perception test with continuous speech-spectrum, babble, and cocktail party noise, in the right and left ears

\begin{tabular}{|c|c|c|c|c|c|c|c|c|c|c|}
\hline \multirow{2}{*}{ Variable } & \multirow{2}{*}{$\begin{array}{l}\text { Categorical } \\
\text { Variable }\end{array}$} & \multirow{2}{*}{ Noise } & \multirow{2}{*}{ Ear } & \multicolumn{2}{|c|}{$\leq 26$ years } & \multicolumn{2}{|c|}{$>26$ years } & \multirow{2}{*}{ p-value } & \multicolumn{2}{|c|}{$\begin{array}{l}\text { 95\% Confidence } \\
\text { Interval }\end{array}$} \\
\hline & & & & Mean & SD & mean & SD & & $\begin{array}{l}\text { Lower } \\
\text { Limit }\end{array}$ & $\begin{array}{l}\text { Upper } \\
\text { Limit }\end{array}$ \\
\hline SPT & Age & CS & $\mathrm{RE}$ & 94.73 & 8.63 & 93.11 & 9.09 & 0.5681 & -4.06 & 7.29 \\
\hline SPT & Age & B & $\mathrm{RE}$ & 86.70 & 8.77 & 85.68 & 11.66 & 0.7565 & -5.60 & 7.64 \\
\hline SPT & Age & $\mathrm{CP}$ & $\mathrm{RE}$ & 93.44 & 6.94 & 88.00 & 12.00 & 0.0897 & -0.89 & 11.76 \\
\hline SPT & Age & CS & $\mathrm{LE}$ & 95.32 & 7.71 & 93.79 & 6.29 & 0.4972 & -2.98 & 6.03 \\
\hline SPT & Age & B & $\mathrm{LE}$ & 87.18 & 8.65 & 87.90 & 10.36 & 0.8127 & -6.83 & 5.39 \\
\hline SPT & Age & $\mathrm{CP}$ & $\mathrm{LE}$ & 92.56 & 5.77 & 89.80 & 9.78 & 0.2859 & -2.42 & 7.94 \\
\hline
\end{tabular}

Statistically significant values $(p \leq 0.05)$ - mixed-effects linear regression model

Captions: SD = standard deviation; $\mathrm{SPT}=$ speech perception test; $\mathrm{RE}=$ right ear; $\mathrm{LE}=$ left ear; $\mathrm{CS}=$ continuous speech-spectrum noise; $\mathrm{B}=$ babble; $\mathrm{CP}=$ cocktail party

As for sex, females obtained higher mean scores in all listening situations with noise. However, this difference was significant only with babble noise for both ears and continuous speech-spectrum and cocktail party noise in the left ear (Table 5).

Table 5. Influence of sex on the results of the speech perception test in continuous speech-spectrum, babble, and cocktail party noise, in the right and left ears

\begin{tabular}{|c|c|c|c|c|c|c|c|c|c|c|}
\hline \multirow{2}{*}{ Variable } & \multirow{2}{*}{$\begin{array}{c}\text { Categorical } \\
\text { Variable }\end{array}$} & \multirow{2}{*}{ Noise } & \multirow{2}{*}{ Ear } & \multicolumn{2}{|c|}{ Males } & \multicolumn{2}{|c|}{ Females } & \multirow{2}{*}{$\mathrm{p}$-value } & \multicolumn{2}{|c|}{$\begin{array}{l}\text { 95\% Confidence } \\
\text { Interval }\end{array}$} \\
\hline & & & & Mean & SD & mean & SD & & $\begin{array}{l}\text { Lower } \\
\text { Limit }\end{array}$ & $\begin{array}{l}\text { Upper } \\
\text { Limit }\end{array}$ \\
\hline SPT & Sex & CS & $\mathrm{RE}$ & 92.59 & 9.48 & 94.90 & 8.32 & 0.4293 & -8.17 & 3.56 \\
\hline SPT & Sex & B & $\mathrm{RE}$ & 82.09 & 10.77 & 89.22 & 8.81 & $0.0332^{*}$ & -13.64 & -0.61 \\
\hline SPT & Sex & $\mathrm{CP}$ & $\mathrm{RE}$ & 87.23 & 11.35 & 93.30 & 8.33 & 0.0722 & -12.74 & 0.59 \\
\hline SPT & Sex & CS & $\mathrm{LE}$ & 91.46 & 9.09 & 96.84 & 3.69 & $0.0323^{*}$ & -10.24 & -0.50 \\
\hline SPT & Sex & B & $\mathrm{LE}$ & 83.15 & 10.91 & 90.78 & 6.71 & $0.0174^{*}$ & -13.80 & -1.46 \\
\hline SPT & Sex & $\mathrm{CP}$ & $\mathrm{LE}$ & 86.95 & 9.01 & 94.30 & 5.64 & $0.0066^{*}$ & -12.46 & -2.24 \\
\hline
\end{tabular}

*Statistically significant values ( $\mathrm{p} \leq 0.05)$ - mixed-effects linear regression model

Captions: $\mathrm{SD}=$ standard deviation; $\mathrm{SPT}=$ speech perception test; $\mathrm{RE}=$ right ear; $\mathrm{LE}=$ left ear; $\mathrm{CS}=$ continuous speech-spectrum noise; $\mathrm{B}=$ babble; $\mathrm{CP}=$ cocktail party

\section{DISCUSSION}

The three types of noise negatively influenced speech perception compared to listening in silence. Also, the subjects had worse performance with babble noise, followed by cocktail party and continuous speech-spectrum noise (Table 2).

Similar results were found in a study by Kawasaki and collaborators ${ }^{10}$, who assessed schoolchildren's speech perception in silence and white and babble noise. The authors found that subjects performed worse with the babble noise.
Caporali and Silva ${ }^{8}$ assessed the effects of age and hearing loss on adults' and older adults' speech perception. To do so, the authors assessed their speech perception in silence, spread-spectrum noise, and cocktail party noise. They found that speech noise had greater sensitivity to show the effects of hearing loss and age on speech perception.

Another study, by Mantelatto ${ }^{16}$, compared the results of the Speech Recognition Index in white noise and cocktail party noise and obtained similar results. They applied the test to normally hearing young people 
and found that cocktail party had a greater interference on their speech intelligibility than white noise.

The psychoacoustic characteristics of babble and cocktail party can explain people's worse performance with these noises. They create a more difficult listening condition than continuous noise, possibly because they are irregular and have a speech spectrum and amplitude modulation ${ }^{10}$. Moreover, high-pitched noises may mask some phonemes in this frequency range, such as fricatives and plosives, impairing speech understanding ${ }^{8,25}$. This may explain the worse performance when using babble noise since it has higher frequencies than the cocktail party noise (Table 1 ).

The importance of high frequencies to speech perception has been demonstrated since the $1950 \mathrm{~s}^{26-28}$. One study, for example, investigated the percentage concentration of speech energy in each region of the octave band and the percentage contribution of each of these regions to speech intelligibility ${ }^{26}$. They found that low frequencies (below $500 \mathrm{~Hz}$ ) concentrate $60 \%$ of speech energy and contribute with only $5 \%$ to intelligibility, while high frequencies (above $1000 \mathrm{~Hz}$ ) concentrate only $5 \%$ of speech energy and contribute with $60 \%$ to speech intelligibility. Thus, the inaudibility of these sounds can generate speech perception difficulties at conversational levels since auditory acuity for highpitched phonemes, such as plosives and fricatives, will be impaired. Moreover, this inaudibility may also lead to difficulties differentiating voiced from voiceless sounds, further impairing speech perception in noisy environments because of the environmental sounds that occur simultaneously with the target stimulus ${ }^{29}$.

Besides the psychoacoustic characteristics of noise, how the auditory system processes stimuli when listening to speech in different noises, which can also explain the worse performance with speech noises, must be considered. In noisy environments, speech perception requires different skills, depending on the noise used. In the case of continuous noise, auditory closure is the most used, whereas, for speech noise, it is figure-ground (although it also requires auditory closure $)^{30}$.

The worse performance in sentence recognition in speech noise may also be related to the acoustic, linguistic, semantic, and circumstantial cues required for speech perception. When listening occurs in unfavorable settings, such as noisy environments, these cues diminish and make the process even more difficult for the listener. The situation is even worse in the specific case of speech noise, as it not only deprives of cues but also provides false cues with its speech murmur that further increase the need for attention and memory required for speech understanding ${ }^{8,10}$. This confirms the results obtained in this study, in which the subjects had worse performance with babble and cocktail party noise (Table 2).

Listeners can use acoustic cues to differentiate the voices of the target stimulus from those present in the noise. Acoustic cues refer to the acoustic characteristics of a stimulus, such as frequency, intensity, and duration. Therefore, when the target stimulus and the noise have similar frequencies, such cues decrease and the demand for attention increases, impairing speech perception ${ }^{1,8,10,31,32}$. This may explain the worse performance of the subjects in this study with babble noise since its mean frequency was closer to that of the speech stimulus than the cocktail party noise (Tables 1 and 2).

Information processing in the auditory system as a variable and checked for differences in responses between the ears was taken into account. Data analysis revealed no difference between the responses of the right and left ears in any of the listening situations. This result may have been influenced in this study by the eligibility criteria of the subjects (who should have normal hearing, without important differences in thresholds between the ears), by their lack of preference for listening with either ear (as requested during the initial interview), and by the absence of complaints or history of hearing difficulties.

Kawasaki et al. ${ }^{10}$ and Spyridakou et al..$^{33}$ obtained similar results. In these studies, they found no differences in performance between the ears in any of the listening situations. However, in the study by Caporali and Silva ${ }^{8}$, the researchers found a difference between the responses of the two ears in all the individuals they assessed.

Regarding age, no difference was found in any of the listening situations in either ear (Tables 3 and 4). This result can be explained by the age range established in the inclusion criteria to avoid any interference of the auditory pathway maturation process and auditory processing decline due to aging ${ }^{34-36}$.

However, Caporali and Silva ${ }^{8}$ found age-related differences when using cocktail party noise, in which older subjects had a worse performance. To some extent, this corroborates the findings in the literature regarding the hearing of older adults.

Females had a better performance than males (Table 5) with babble noise, both for the right $(p=$ 
$0.0332)$ and left ear $(p=0.0174)$, and with continuous speech-spectrum noise and cocktail party, for the left ear $(p=0.0323$ and $p=0.0066$, respectively). No similar studies were found in the literature analyzing the sexes and ears in these terms. A study assessed speech perception in babble noise in 40 women and 29 men with normal hearing and found no difference between the sexes, unlike the results of the present study $^{33}$.

The main objective of this study was to investigate the influence of different types of noise on speech perception. The results corroborate those found in the literature, which indicates that speech-spectrum noise has a greater influence. This was strongly evidenced in the studies cited above, in which cocktail party and babble noise proved to be more detrimental to speech recognition than white noise $e^{4,8,10,16}$.

Standardizing speech perception in speechspectrum noise (as approached in this study) contributed to distinguish neurological changes from central auditory processing impairment. Furthermore, these results can be used in low-redundancy tests of central auditory processing ${ }^{37}$.

Finally, it is important to stress the difficulty of finding information in the literature that would allow us to compare the influence of speech-spectrum noises on perception, as well as data explaining why a given speech noise had better sensitivity than the others. What was observed in the literature is that research tends to compare continuous and speech noises and their effects on the recognition process.

\section{CONCLUSION}

The results of the speech perception test were influenced by the types of noise used in this study. The subjects had a worse performance in the babble noise, followed by the cocktail party noise and the continuous speech-spectrum noise.

\section{REFERENCES}

1. Mendes BCA, Barzagui L. Percepção e produção da fala e deficiência auditiva. In: Bevilacqua MC, Martinez MAN, Balen SA, Pupo AC, Reis ACMB, Frota $S$, organizadores. Tratado de Audiologia. 1a ed. Santos: Livraria Santos Editora LTDA; 2011. p.653-70.

2. Jacob RTS, Monteiro NFG, Molina SV, Bevilacqua MC, Lauris JRP, Moret ALM. Percepção da fala em crianças em situação de ruído. Arq. Int. Otorrinolaringol. 2011;15(2):163-7.

3. Magalhães LA, Cimonari PM, Novaes BCDAC. Avaliação de percepção de fala em crianças com deficiência auditiva usuárias de aparelho de amplificação sonora: a questão do instrumento e seus critérios. Rev. Soc. Bras. Fonoaudiol. 2007;12(3):221-32.

4. Ribas A, Tozi G. O teste fala no ruído ipsilateral em crianças com distúrbio de aprendizagem. Tuiuti: Ciência e Cultura. 2005;3(37):39-52.

5. Carvalho LMAD, Gonsalez ECDM, Iorio MCM. Speech perception in noise in the elderly: interactions between cognitive performance, depressive symptoms, and education. Braz. J. Otorhinolaryngol. 2017;83(2):195-200.

6. Mattys SL, Davis MH, Bradlow AR, Scott SK. Speech recognition in adverse conditions: a review. Lang. Cogn. Process. 2012;27(7-8):953-78.

7. Thompson EC, Krizman J, White-Schwoch T, Nicol T, Estabrook R, Kraus N. Neurophysiological, linguistic, and cognitive predictors of children's ability to perceive speech in noise. Dev. Cogn. Neurosci. 2019;39(1):100672.

8. Caporali SA, Silva JAD. Reconhecimento de fala no ruído em jovens e idosos com perda auditiva. Rev. Bras. Otorrinolaringol. 2004;70(4):525-32.

9. Gama MR. Percepção da fala: uma proposta de avaliação qualitativa. São Paulo: Pancast; 1994.

10. Kawasaki TH, Silva TGC, Queiroz DS, BrancoBarreiro FCA. Comparação da inteligibilidade de fala de escolares na presença de ruído branco e de burburinho. Rev. Equilíbrio Corporal Saúde. 2011;3(1):16-24.

11. Henriques MO, Costa MJ. Reconhecimento de sentenças no ruído, em campo livre, em indivíduos com e sem perda auditiva. Rev. CEFAC. 2011;13(6):1040-7.

12. Nilsson M, Soli SD, Sullivan JA. Development of the hearing in Noise Test for the measurement of speech reception thresholds in quiet and in noise. JASA. 1994;95(2):1085-99.

13. Santos SND, Daniel RC, Costa MJ. Estudo da equivalência entre as listas de sentenças em português. Rev. CEFAC. 2009;11(4):673-80.

14. Costa MJ. Listas de sentenças em português: apresentação e estratégias e aplicação na audiologia. Santa Maria: Pallotti; 1998.

15. Corteletti LCBJ. Mascaramento clínico. In: Bevilacqua MC, Martinez MAN, Balen SA, Pupo AC, 
Reis ACMB, Frota S, organizadores. Tratado de Audiologia. $1^{\mathrm{a}}$ ed. Santos: Livraria Santos Editora LTDA 2011. p.101-22.

16. Mantelatto SAC. Percepção da Inteligibilidade de Fala por Sujeitos Jovens com audição normal frente à ruídos competitivos [Thesis]. Ribeirão Preto (SP): Faculdade de Filosofia Ciências e Letras de Ribeirão Preto da Universidade de São Paulo; 1998.

17. Costa MJ, Iorio MCM, Albernaz PLM, Cabral Junior $E F$, Magni AB. Desenvolvimento de um ruído com espectro de fala. Acta Awho. 1998;17(2):84-9.

18. Hagerman B. Sentences for testing speech intelligibility in noise. Scand Audiol. 1982;11(2):79-87.

19. Plomp R, Mimpen AM. Improving the reliability of testing the speech reception threshold for sentences. Audiology. 1979;18(1):43-52.

20. OMS: Organização Mundial de Saúde. Hearing impairment grades. [Homepage on the Internet] [accessed on $2017 \mathrm{Apr} 10]$. Available at: http://www.who.int/pbd/ deafness/ hearing_impairment_grades/en/

21. Costa MJ, Santos SN, Lessa AH, Mezzomo CL. Proposal for implementing the Sentence Recognition Index in individuals with hearing disorders. CoDAS. 2015;27(2):148-54.

22. Buzo BC, Lopes JAS. Speech recognition in noise in individuals with normal hearing and tinnitus. Audiol., Commun. Res. [Journal on the Internet]. 2017 [accessed on 2021 March 10]; 22: e1693. Available at: http://www.scielo. $\mathrm{br} / \mathrm{scielo}$. php? script $=$ sci_arttext\&pid $=$ S2317 64312017000100308\&Ing=en. Epub Apr 10, 2017. https://doi.org/10.1590/2317-6431-2016-1693.

23. Costa MJ, lorio MCM, Mangabeira-Albernaz PL. Reconhecimento de fala: desenvolvimento de uma lista de sentenças em português. Acta Awho. 1997;16(4):164-73.

24. Costa MJ. Desenvolvimento de listas de sentenças em português [Dissertation]. São Paulo (SP): Universidade Federal de São Paulo; 1997.

25. Cielo CA, Casarin MT. Sons fricativos surdos. Rev. CEFAC. 2008;10(3):352-8.

26. Fletcher $\mathrm{H}$. Speech and hearing communication. New Jersey: D.Van Nostrand; 1953.

27. Behlau M, Russo ICP. Percepção da fala: análise acústica. São Paulo: Lovise; 1993.
28. Pereira LD, Schochat E. Processamento auditivo central: manual de avaliação. São Paulo: Lovise; 1997.

29. Mukari SZMS, Yusof Y, Ishak WS, Maamor N, Chellapan K, Dzulkifli MA. Contribuições relativas das funções auditivas e cognitivas no reconhecimento da fala no silêncio e no ruído entre idosos. Braz. J. Otorhinolaryngol. 2010;86(2):149-56.

30. Santos LMD, Lemos SMA, Rothe-Neves R. Perceptual confusions among consonants in Brazilian Portuguese as a function of noise. Audiol., Commun. Res. 2014;19(2):145-52.

31. Coffey EBJ, Mogilever NB, Zatorre RJ. Speech-innoise perception in musicians: a review. Hear Res. 2017;352:49-69.

32. Yates KM, Moore DR, Amitay S, Barry JG. Sensitivity to melody, rhythm, and beat in supporting speechin-noise perception in young adults. Ear Hear. 2019;40(2):358-67.

33. Spyridakou C, Rosen S, Dritsakis G, Bamiou DE. Adult normative data for the speech in babble (SiB) test. Int. J. Audiol. 2020;59(1):33-8.

34. Leibold LJ. Speech perception in complex acoustic environments: developmental effects. J Speech Lang Hear Res. 2017;60(10):3001-8.

35. Lawrence BJ, Jayakody DMP, Henshaw $H$, Ferguson MA, Eikelboom RH, Loftus AM et al. Auditory and cognitive training for cognition in adults with hearing loss: a systematic review and meta-analysis. Trends Hear. 2018;22: 2331216518792096.

36. Kopper H, Teixeira AR, Dorneles S. Desempenho cognitivo em um grupo de idosos: influência de audição, idade, sexo e escolaridade. Arq. Int. Otorrinolaringol. 2009;13(1):39-43.

37. Chermak GD, Bamiou DE, lliadou V, Musiek FE. Practical guidelines to minimise language and cognitive confounds in the diagnosis of CAPD: a brief tutorial. Int. J. Audiol. 2017;56(7):499-506. 